\title{
Usage of Census Results for Planning and Evaluating Various Government Policies and Intervention Programs
}

\author{
Teuta Xhindi \\ PHD candidate \\ European University of Tirana, Economic Faculty \\ Information, Statistics and Mathematic Department \\ Ogerta Elezaj \\ PHD candidate \\ National Institute of Statistics \\ Director of Information Technology Department
}

Doi:10.5901/ajis.2013.v2n8p635

\section{Abstract}

During 2011 Albania conducted the 11th Population and Housing Census. The census results are vital for the country for planning and evaluating various government policies and intervention programs at national and regional levels.

The main findings of the census are:

- The population has declined around 8.0 per cent, compared to the 2001 census

- For the first time, the population living in urban areas has exceeded the population living in rural areas

After the availability of census data, the main challenge for policy making is how these data can be used to guide the investment funds in infrastructure and services and to help the local authorities in designing strategies in favor of vulnerable groups.In this paper the focus will be to explain the main findings of the census and the impact that have in the government policies. A questionnaire will be used to collect information from the local authorities about:

- Are census main findings affecting people in their community?

- Do the local authorities meet their needs from census results?

- Does the internal movements play important role in their intervention programs?

- Is the information gathered important to plan a wide range of public services such as

- Schools: for children now and in the future in their area

- Social housing: for persons who need a social place to live

- Transport: to and from work

- Healthcare: facilities that everyone can access easily etc

Keywords: Census, official statistics, local governance, etc.

\section{Introduction}

During 2011 Albania conducted the 11th Population and Housing Census. The census results are vital for the country for planning and evaluating various government policies and intervention programs at national and regional levels.

With the availability of census results, the country can now use up-to-date socio-economic data at national, regional and local levels.

The Albanian census collected data about the building/dwelling characteristics, households and individuals.

- Household information included tenure status, ownership, availability of goods and facilities.

- The individual questionnaire collected data for each individual organized in different modules: Main demographic characteristics - age, sex, marital status, place of birth and citizenship

- Migration module - internal and international movements was collected

- Education module -data on persons that were currently attending school, highest level of completed education, number of years of completed education and literacy

- Employment module -employment and unemployed characteristics of the population, as well as place of work and mode of travel to work 
- Ethno-cultural characteristics module -ethnicity affiliation and religion based on free declarations of the individuals including the alternative not to answer.

Based on the information collected and processed, the results of the 2011 Population and Housing Census in Albania are a clear picture of the socio-economic situation of the whole country or small spatial areas. Moreover, the increased availability of digitized census data means increased ability to convert data into information for research, planning, and policy identifying geographically the information for small areas.

Benefits of Using Census Data are:

- In Albania as in the other countries, the census is the only source of data that attempts to obtain a complete enumeration of the population.

- It is the only source available that provides detailed information on socio-economic indicators as well as environmental factors (housing, sanitation, access to water).

- Information is provided for very small sub-populations, such as villages, commune/municipalities, districts and prefectures.

On the other hand there are two main limitations:

- Timing- Albanian Population and Housing Censusis carried out every ten year.

- Only a limited set of information can be collected by the census

\section{Main findings in Albania}

\subsection{Demography findings:}

On 1 October 2011, the usual resident population in Albania was 2800 138, with 50.1\% male. The average age of the population increased from 30.6 in 2001 to 35.3 years.

The population has declined with around 8\%, compared to the 2001 Census where the population was 3069275.

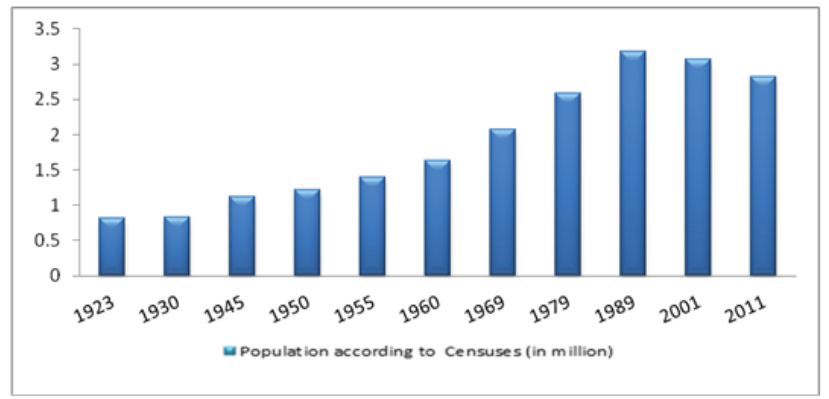

Population dynamics are determined by four factors: births, deaths, immigration and emigration.

The effect of each factor in the size of population is given by the population balance equation:

$\mathrm{P}_{2011}=\mathrm{P}_{2001}+\mathrm{B}-\mathrm{D}+\mathrm{I}-\mathrm{E}$.

The decrease of resident population in Albania is supposed to be because of two main reasons:

- The decrease of fertility

- Continuous large-scale emigration

\subsubsection{Natural increase:}

The number of births per year has decreased significantly, from about 53 thousand in 2001 to about 34 thousand in 2011.

- This means a positive but declining natural increase.

- The number of deaths per year has remained stable at around 20 thousand.

- The decline of fertility is supposed to be one of the factors that has a big impact in the population decline. 


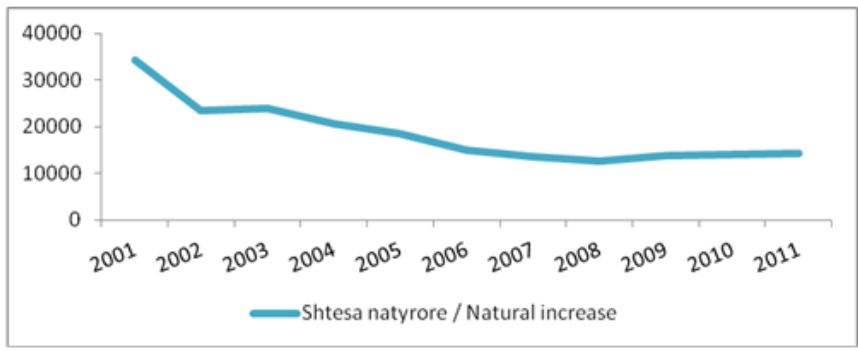

\subsection{Education findings:}

Education in Albania is covered by public and private schools. In recent years, the Albanian education system has made substantial progress towards the general compliance with others European educational systems.

The first two levels of education, primary and lower secondary, a total of 9 years education, are currently compulsory in the country. At university level, the Bologna system ( $3+2$ years) is nowadays followed by all universities, public and private. The 2011 census included four questions on educational characteristics, maintaining comparability with data from the 2001 census and enabling the calculation of key indicators on education.

Illiteracy level for the population 10 years and over is $2.75 \%: 3.7 \%$ for females and $1.7 \%$ for males

- $96,2 \%$ of the population 10 years and over are currently attending or have completed school

- 1,0\% of the age group of 7-15 years old never attended school

Planning and provision of services in the educational system according to the number of the population and the age of the children- such data on target populations is also of use in program planning concerned with building, classroom, teacher and equipment needed. A special attention should be given to the education data of Tirana and Durres, which are the only regions in Albania where the population is increased and will continue to increase in the coming years.

Also, in Albania there is a gap between illiterate female and male which means that further actions should be taken to decline this gap.

\subsubsection{Emigration}

Based on the data of the 2011 and 2011 Censuses it is estimated that:

- Between 2001-2011 Censuses around 500 thousand persons have emigrated.

- Between 1989-2001 Censuses around 600 thousand persons have emigrated.

- In the age group with highest emigration (20-39 years-old), the decrease in the number of females is greater than that of males.

These findings are evident if you analyze the shape of the population pyramid.

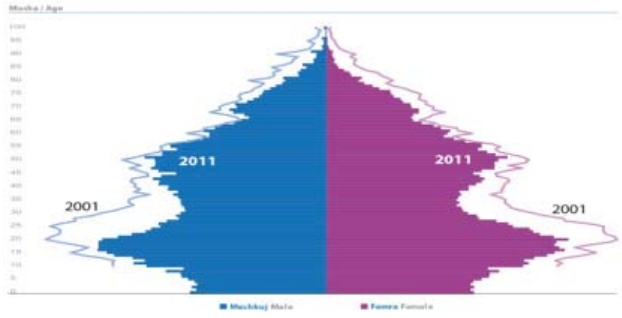

Population density at the national level is 97 residents per square kilometre compared to 107 residents per square kilometre in 2001.

The population density in the prefectures of Tirana and Durres indicates higher values compared to other prefectures, respectively 454 and 343 persons per square kilometre.

This because these are the only prefectures that have an increase in the number of population compared to 2001 
Census.

The internal movements of the population from one region to another, or within the same region, have continued also in the inter-censual period 2001-2011, continuing to impact on the population changes at local level. In comparison to the previous census, about $10 \%$ of the population has changed the place of usual residence within the country and almost $18 \%$ of population has emigrated.

For the first time, the population living in urban areas has exceeded the population living in rural areas. It was 53.5 $\%$ in urban areas and $46.5 \%$ in rural areas.

Figure 5: Percentage of the resident population in urban and rural areas according to 2001 and 2011 censuses

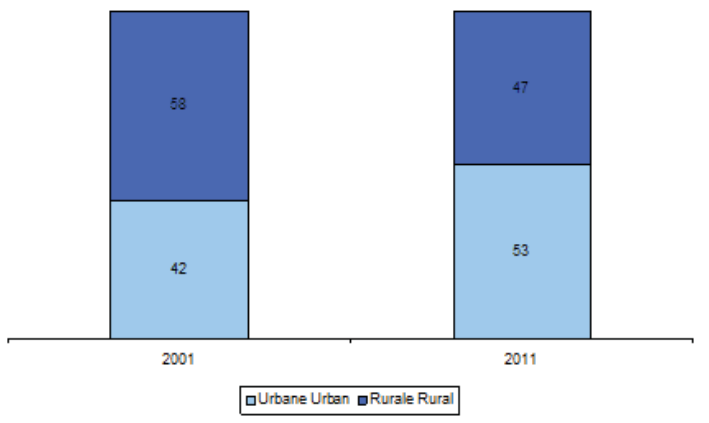

In the frame of Urban Planning and Development Strategy, Albanian Government should review the typology of Albanian regions, as well as the types of rural communes; and secondly, definition of urban/rural should be changed based on the population distribution and population structure.

\subsection{Disability findings:}

The 2011 census identified for the first time the population with limitations in the functioning of basic activities. The main objective was to determine the number of persons with disability, type of disability, as well as their demographic and socio-economic profiles.

A total of 137435 people reported that they had some sort of disability that prevented them from the full participation in their activities of daily life. In the age 15 and older the percentage was $6.2 \%$. From these, $45.3 \%$ are males and $54.7 \%$ females. Most of the people who reported disabilities have stated that they have suffered in mobility and seeing. The disability is higher in women compared to men. This characteristic seems depending on the civil status, with higher prevalence in the married women and widows.

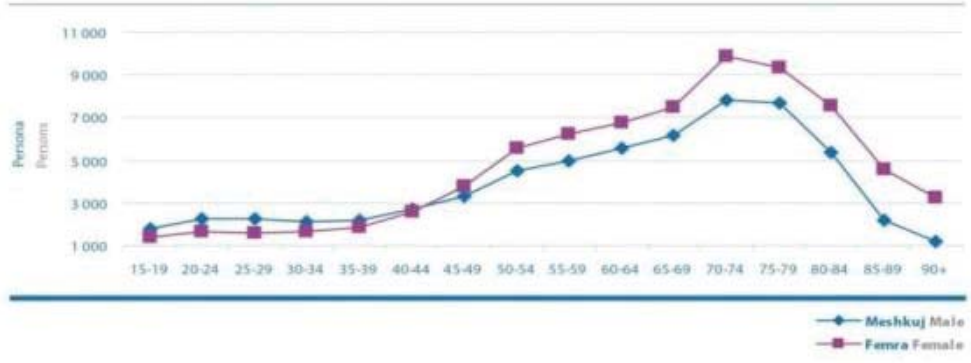

All this data available for the first time in Albania will be the roadmap for designing and implementing the Albanian National Strategy on People with Disability. The main objectives of all policies shall be to improve the overall living conditions of people with disabilities in Albania and to achieve lasting results in including them in all aspects of life to enjoy the full range of civil and human rights. 


\section{Assessment of usage of census results for planning and evaluating intervention programs by local authorities}

The Population and Housing Censusresults were published in May 2013 in the prefecture level.

Based on the law, the budget and the grants are disbursed to each municipality/commune based on the resident population per municipality/commune. The disbursements of the funds in 2013 were done based on the census results. The decrease in the number of resident population in mostly of the municipality/commune affected the total funds distributed by Albania Ministry of Finance.

Albania is divided into 12 administrative prefectures .These prefectures include 36 districts and 373 municipalities. The municipality/commune councils are the representative bodies, their members come from the elected municipal and commune councils according to the population size.The regional councils are fully independent state bodies that function according to specific legal statues and enactments in order to implement regional development policy in cooperation with the State. They work as a facilitator between the local and state government. A primary competency of the regional councils is to develop strategies, which are then directed to the relevant departments of the state ministry. The regional councils also serve to manage disbursements of the state budget toward investments with regional ramifications. Primary examples include: rural road infrastructure, pre-university level education, health systems, tourism development (visitor services), regional transport, and cultural heritage. These competencies are set forth in the constitution and stipulated through local government legislation.

Considering the above, we have raised this two research questions:

- Do the local authorities and other structures have information about Census 2011?

- Do the local authorities and other structures know the importance of using census results to achieve their goals?

\section{Methodology and data collection}

To respond the two questions, we used data collected from 62 questionnaires (see attached)

The questionnaires are fulfilled by employers in charge of planning and policy taking.

From 12 prefectures there were randomly selected 5 municipalities/communes for collecting data.

The data were analyzed in SPSS software and there were used mix questions, open and closed ones.

\section{Survey Analysis and Results}

Analyzing the answersturns out that:

- $93.5 \%$ have information about Census 2011 results, but only $66.1 \%$ from them know that census data affect budget or grants and how.

- Only $45.2 \%$ of respondents,as local authorities, meet their needs from census results.

- $67.7 \%$ declared that the internal movements play an important role in their intervention programs.

- Mostly of respondents sow the information gathered from census, important to plan a wide range of public services such as: schools(96.8\%), social housing(83.9\%), transport (75.8\%), healthcare (95.2\%).

\section{Conclusions}

- The results of the census directly affect people in community. The information gatheredshould be used to plan a wide range of public services, many provided by local authorities, which should be there for everyone to use. The more we know about the people in our community, the better local authorities can understand and meet their needs.

- Local government has anxiously awaited the Census 2011 data, and now that it is available and enabling efficient use of census data can allow local government to quickly prepare grant applications and perform ad hoc analysis of trends to fulfill their needs for data.

- Based on the Population and Housing Census 2011, among the main results would have been setting the boundaries of urban agglomeration consisting of central cities, suburbs and peri-urban communes and classification of all communes aggregated based on indicators of the importance and urbanization, sector 
structure and specialization of economic development (tourism, industry, mining), and natural conditions for agriculture. This classification will provide a tool to support the territorial analysis, policy evaluation, and urban and regional planning.

- Urban sprawl is becoming a significant problem in many countries with high population density. In Albania urban growth, urban sprawl is noticed in the most important cities mainly located in the western part of the country. There is a need to analyze the urban sprawl in Albania and to predict how it will be continuing the enlargement of the major cities in the future.

\section{References}

Albanian Institute of Statistics, "Albania in Figures 2009", Tiranë.

Albanian Institute of Statistics, "Population and Housing Census 2001", Tiranë 2002.

Albanian Institute of Statistics, "Population and Housing Census 2011", Tiranë 2012.

Macro International Inc2010, (ADHS 2010), Demographic and health survey in Albania 2008/2009.

Azzaria, C.; Carletto, C. "Modeling migration dynamics in Albania: a hazard function approach", World Bank, Washington DC, USA.

Albanian Institute of Statistics, "Population projections for Albania 2001-2021", Tiranë 2004.

Lerch, M." Fertility Decline During Albania's Societal Crisis and its Subsequent Consolidation"

Caselli, G.;Vallin, J. "Population Dynamics: Movement and Structure", "La Sapienza", UniversitadegliStudi di Roma, Italy, Institut National D'etudesDemographiques (INED), Paris, France.

\section{Annexes}

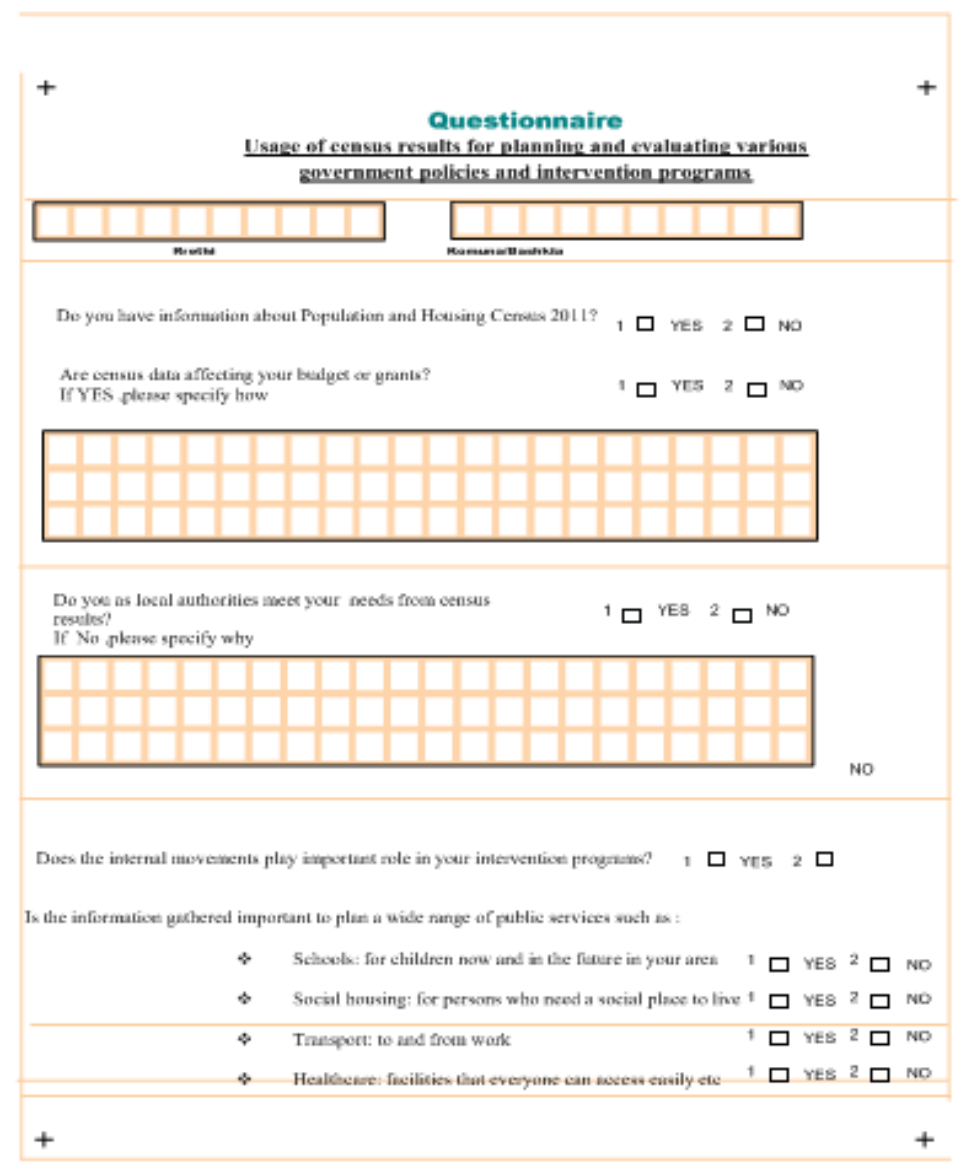


Question 1

\begin{tabular}{|cc|c|c|c|c|}
\hline & & Frequency & Percent & Valid Percent & Cumulative Percent \\
\hline \multirow{4}{*}{ Valid } & 1 & 58 & 93.5 & 93.5 & 93.5 \\
& 2 & 4 & 6.5 & 6.5 & 100.0 \\
& Total & 62 & 100.0 & 100.0 & \\
\hline
\end{tabular}

Question 2

\begin{tabular}{|cc|c|c|c|c|}
\hline & & Frequency & Percent & Valid Percent & Cumulative Percent \\
\hline \multirow{4}{*}{ Valid } & 1 & 41 & 66.1 & 66.1 & 66.1 \\
& 2 & 21 & 33.9 & 33.9 & 100.0 \\
& Total & 62 & 100.0 & 100.0 & \\
\hline
\end{tabular}

\section{Question 3}

\begin{tabular}{|cc|c|c|c|c|}
\hline & & Frequency & Percent & Valid Percent & Cumulative Percent \\
\hline \multirow{4}{*}{ Valid } & 1 & 28 & 45.2 & 45.2 & 45.2 \\
& 2 & 34 & 54.8 & 54.8 & 100.0 \\
& Total & 62 & 100.0 & 100.0 & \\
\hline
\end{tabular}

\section{Question 4}

\begin{tabular}{|cc|c|c|c|c|}
\hline & & Frequency & Percent & Valid Percent & Cumulative Percent \\
\hline \multirow{4}{*}{ Valid } & 1 & 42 & 67.7 & 67.7 & 67.7 \\
& 2 & 20 & 32.3 & 32.3 & 100.0 \\
& Total & 62 & 100.0 & 100.0 & \\
\hline
\end{tabular}

Question 5_1

\begin{tabular}{|cc|c|c|c|c|}
\hline & & Frequency & Percent & Valid Percent & Cumulative Percent \\
\hline \multirow{4}{*}{ Valid } & 1 & 60 & 96.8 & 96.8 & 96.8 \\
& 2 & 2 & 3.2 & 3.2 & 100.0 \\
& Total & 62 & 100.0 & 100.0 & \\
\hline
\end{tabular}

Question 5_2

\begin{tabular}{|cc|c|c|c|c|}
\hline & & Frequency & Percent & Valid Percent & Cumulative Percent \\
\hline \multirow{4}{*}{ Valid } & 1 & 52 & 83.9 & 83.9 & 83.9 \\
& 2 & 10 & 16.1 & 16.1 & 100.0 \\
& Total & 62 & 100.0 & 100.0 & \\
\hline
\end{tabular}

Question 5_3

\begin{tabular}{|cc|c|c|c|c|}
\hline & & Frequency & Percent & Valid Percent & Cumulative Percent \\
\hline \multirow{4}{*}{ Valid } & 1 & 47 & 75.8 & 75.8 & 75.8 \\
& 2 & 15 & 24.2 & 24.2 & 100.0 \\
& Total & 62 & 100.0 & 100.0 & \\
\hline
\end{tabular}

Question 5_4

\begin{tabular}{|cc|c|c|c|c|}
\hline & & Frequency & Percent & Valid Percent & Cumulative Percent \\
\hline \multirow{4}{*}{ Valid } & 1 & 59 & 95.2 & 95.2 & 95.2 \\
& 2 & 3 & 4.8 & 4.8 & 100.0 \\
& Total & 62 & 100.0 & 100.0 & \\
\hline
\end{tabular}

